\title{
STUDI PERBANDINGAN LIQUID LIMIT MENGGUNAKAN ALAT FALL CONE DAN CASAGRANDE DENGAN VARIASI UKURAN BUTIR TANAH
}

\author{
Indra $^{1}$ dan Gregorius Sandjaja Sentosa ${ }^{2}$ \\ ${ }^{1}$ Program Studi Sarjana Teknik Sipil, Universitas Tarumanagara, Jl. Letjen S. Parman No.1 Jakarta \\ Email: acenindra123@yahoo.com \\ ${ }^{2}$ Program Studi Sarjana Teknik Sipil, Universitas Tarumanagara, Jl. Letjen S. Parman No.1 Jakarta \\ Email: gregorius@ft.untar.ac.id
}

\begin{abstract}
ABSTRAK
Pengujian liquid limit dapat dilakukan dengan menggunakan dua alat yakni alat Casagrande dan alat fall cone. Penggunaan alat Casagrande mengacu pada standar ASTM dan penggunaan alat fall cone mengacu pada standar British Standard. Dalam kedua alat tersebut terdapat dua jenis metode yang dapat digunakan yakni metode one-point dan metode multi-point. Pengujian liquid limit menggunakan tanah yang lolos saringan no.40 yang terdiri dari pasir halus, lanau dan lempung. Analisis data dilakukan untuk mencari korelasi distribusi ukuran butir tanah dengan nilai liquid limit menggunakan kedua alat dan kedua metode tersebut. Berdasarkan hasil analisis data tersebut, tidak ditemukan korelasi antara distribusi ukuran butir tanah dengan nilai liquid limit. Namun berdasarkan hasil analisis data tersebut diperoleh korelasi nilai liquid limit dengan menggunakan kedua alat dan metode tersebut memiliki nilai yang hampir sama.
\end{abstract}

Kata kunci: liquid limit, alat Casagrande, alat fall cone, ASTM, British Standard, metode one-point, metode multi-point, distribusi ukuran butir.

\section{PENDAHULUAN}

Tanah memiliki berbagai macam ukuran butir dan kandungan mineral yang terdiri dari beberapa unsur kimia seperti oksigen, air, kalsium, ferrum, aluminium dan lain sebagainya. Tanah pada dasarnya diklasifikasikan berdasarkan kondisi ukuran butiran yang dapat dibedakan sifat fisiknya antara lain kerikil, pasir, lanau, dan lempung. Terdapat beberapa jenis sistem klasifikasi tanah yang dapat digunakan seperti USCS, AASHTO, USDA, dan lain sebagainya. Untuk menentukan klasifikasi tanah, pengujian specific gravity dan grain size analysis memegang peran penting. Dalam pengujian specific gravity dilakukan untuk mendukung pengujian hydrometer analysis yang terdapat pada pengujian grain size analysis. Sedangkan dalam pengujian grain size analysis dilakukan untuk mencari distribusi ukuran butir tanah.

Pada sistem klasifikasi USCS, tanah diklasifikasikan menjadi dua kategori besar yaitu tanah berbutir kasar yang terdiri dari kerikil dan pasir, dan tanah berbutir halus yang terdiri dari lanau dan lempung. Sampel tanah dapat dikategorikan tanah berbutir kasar apabila sampel tanah yang melewati saringan No.200 kurang dari 50\%, sedangkan untuk kategori tanah berbutir halus apabila sampel tanah yang melewati saringan No.200 lebih dari 50\% (Garcia-Gaines, 2015). Pada tanah dengan butir halus ikatan antara unsur kimia dengan air sangat terikat sehingga masa tanah lempung merupakan lapisan yang lemah serta mineral lempung sangat memengaruhi sifat masa tanah secara keseluruhan (Sutarman, 2013). Mineral lempung menunjukkan karakteristik yang berhubungan dengan air dan plastisitas yang dihasilkan (Sutarman, 2013). Hubungan antara kadar air dan plastisitas tanah dapat ditunjukkan dengan mencari Atterberg limits. Atterberg limits terdiri dari liquid limit (LL), plastic limit (PL), dan plasticity index (PI). Sampel tanah yang digunakan dalam pengujian Atterberg limits merupakan tanah lolos saringan no.40 yang terdiri dari pasir halus, lanau dan lempung. Terdapat dua metode uji laboratorium yang digunakan untuk mencari Atterberg limits yaitu metode Atterberg konvensional dan fall cone. Metode Atterberg konvensional dengan acuan ASTM dan metode fall cone dengan acuan BS 1337:2. Metode Atterberg konvensional cukup banyak digunakan sebagai materi studi, namun dalam metode Atterberg konvensional memakan waktu dan pengalaman praktikan mempengaruhi hasil uji laboratorium. Dalam metode fall cone, pengalaman praktikan tidak berpengaruh dan penggunaan alat fall cone cukup praktis namun alat fall cone hanya dapat dilakukan dalam pengujian liquid limit. Untuk menentukan plastic limit dalam metode fall cone masih menggunakan metode yang sama dengan metode Atterberg konvensional. Terdapat beberapa studi penggunaan alat fall cone untuk menentukan nilai plastic limit seperti yang dilakukan oleh Sivakumar (2009). Dalam studi tersebut, alat fall cone digunakan untuk mencari nilai plastic limit namun alat fall cone harus dimodifikasi dari berat cone sampai tinggi jatuh cone. Belum terdapat standar yang berlaku, sehingga penggunaan alat fall cone hanya pada pengujian liquid limit. 
Dalam studi ini, terdapat dua analisis yang dilakukan yaitu analisis korelasi distribusi ukuran butir tanah dengan nilai liquid limit menggunakan alat Casagrande dan alat fall cone, dan analisis korelasi nilai liquid limit menggunakan alat Casagrande dan alat fall cone. Studi ini bertujuan mencari korelasi nilai liquid limit dengan distribusi ukuran butir dan mencari keakuratan alat yang digunakan untuk mencari nilai liquid limit. Dalam studi ini, data yang diperoleh bersifat ekperimental dan sampel tanah yang digunakan merupakan tanah alami tanpa rekayasa dengan lokasi yang berbeda dengan kategori tanah berbutir halus. Sehingga untuk mendukung studi ini, terdapat beberapa pengujian laboratorium yang akan digunakan.

\section{PENGUJIAN LABORATORIUM}

Dalam studi ini terdapat beberapa uji laboratorium menggunakan sampel tanah yang diambil dari beberapa lokasi di Indonesia, yaitu Jambi, Sumatera Barat, Banten, dan Jawa Barat. Masing-masing sampel tanah diberi identitas sebagai sampel tanah Jambi, Gunung Sarik, Cisoka, dan Cibitung. Terhadap sampel tanah tersebut dilakukan uji index properties meliputi specific gravity, ukuran butir, dan liquid limit.

\section{a. Specific Gravity}

Pada studi ini, pengujian specific gravity mengacu pada standar ASTM D 854-02. Tujuan pengujian adalah untuk menentukan ukuran butir tanah dalam pengujian hydrometer analysis. Hasil specific gravity dapat dilihat pada Tabel 1.

Tabel 1. Hasil pengujian specific gravity pada 4 lokasi berbeda.

\begin{tabular}{lcccc} 
Lokasi & Jambi & Gn. Sarik & Cisoka & Cibitung \\
\hline Gs & 2.63 & 2.73 & 2.63 & 2.77
\end{tabular}

\section{b. Grain Size Analysis}

Pada studi ini, pengujian grain size analysis mengacu pada standar ASTM D 422. Tujuan pengujian ini adalah untuk menentukan distribusi ukuran butir tanah pada setiap lokasi. Pengujian grain size analysis memiliki dua jenis pengujian yaitu pengujian sieve analysis dan pengujian hydrometer analysis. Berdasarkan hal tersebut, sampel tanah pengujian dibagi menjadi dua yaitu sampel tanah berbutir kasar dan sampel tanah berbutir halus. Untuk mendapatkan kedua sampel tersebut, sampel yang dipersiapkan untuk pengujian grain size analysis dicuci dengan menggunakan saringan No.200. Sampel yang tertahan pada saringan merupakan sampel tanah berbutir kasar yang digunakan untuk pengujian sieve analysis, sedangkan tanah yang lolos saringan merupakan sampel tanah berbutir halus yang digunakan untuk pengujian hydrometer analysis. Pengujian dimulai dengan pengujian sieve analysis untuk menentukan distribusi kerikil sampai pasir halus kemudian dilanjutkan dengan pengujian hydrometer analysis untuk menentukan distribusi lanau dan lempung. Hasil grain size analysis dapat dilihat pada Gambar 1.

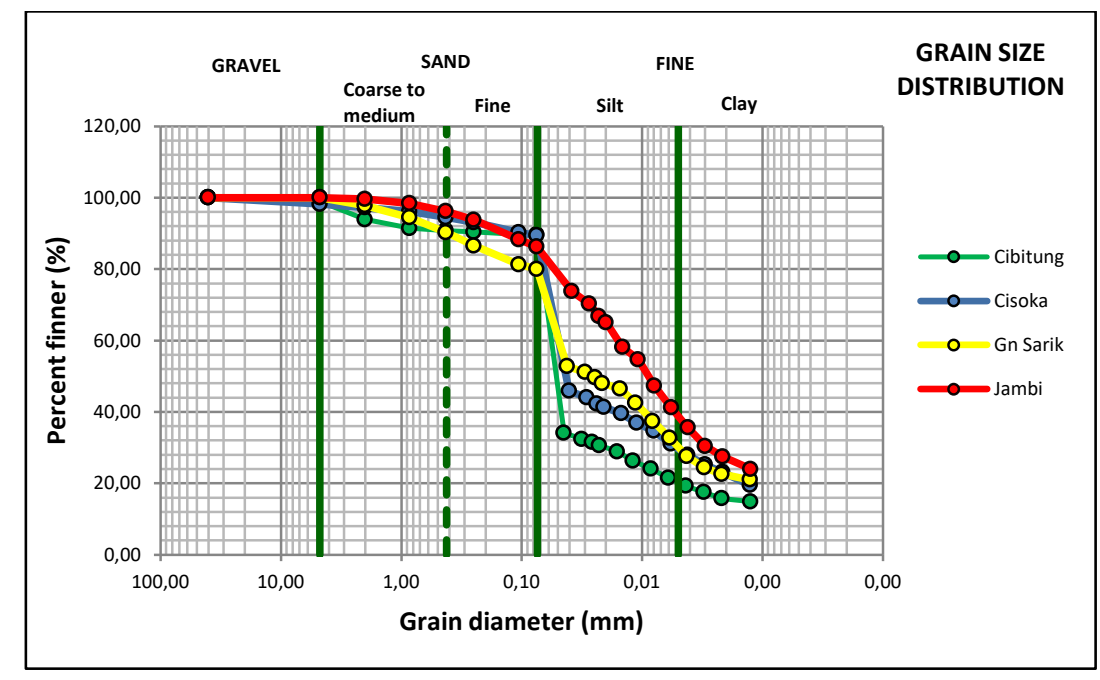

Gambar 1. Kurva pengujian grain size analysis pada 4 lokasi berbeda. 


\section{c. Liquid Limit}

Pada studi ini, pengujian liquid limit mengacu pada standar ASTM D 4318 untuk alat Casagrande dan British Standard 1337:2 untuk alat fall cone. Pada alat Casagrande, pengujian bergantung pada jumlah ketukan yang diperoleh sedangkan pada alat fall cone bergantung pada nilai kedalaman cone yang jatuh. Pengujian dilakukan untuk menentukan nilai liquid limit tanah tiap lokasi yang diuji dengan metode multi-point dan one-point pada setiap alat.

Pada metode multi-point, nilai liquid limit diperoleh dengan melakukan pengujian minimal 3 kali dengan kadar air yang berbeda kemudian diplot ke dalam sebuah grafik membentuk sebuah garis linear. Pada alat Casagrande, nilai liquid limit diperoleh dengan mengambil kadar air pada ketukan 25 dalam kurva linear. Sedangkan pada alat fall cone, nilai liquid limit diperoleh dengan mengambil kadar air pada penetrasi cone 20 mm dalam kurva linear.

Pada metode one-point, nilai liquid limit diperoleh dengan menggunakan rumus yang berlaku pada masingmasing alat. Untuk alat Casagrande, metode one-point diperoleh dengan mengambil kadar air yang memiliki jumlah ketukan mendekati nilai 25 ketukan, sedangkan untuk alat fall cone, metode one-point diperoleh dengan mengambil kadar air yang memiliki kedalaman cone mendekati nilai $20 \mathrm{~mm}$.

Nilai liquid limit alat Casagrande dengan metode one-point dapat diperoleh dari persamaan 1:

$$
L L=w_{n} \times\left(\frac{N}{25}\right)^{0.121}
$$

dengan $\mathrm{LL}=$ nilai liquid limit alat Casagrande dengan metode one-point, $w_{n}=$ kadar air, $\mathrm{N}=$ jumlah ketukan.

Nilai liquid limit alat fall cone dengan metode one-point dapat diperoleh dari persamaan 2:

$$
L L=w_{n} \times \text { factor }
$$

dengan LL= nilai liquid limit alat fall cone dengan metode one-point, $w_{n}=$ kadar air, factor $=$ nilai factor dapat dilihat pada Tabel 2 (British Standar 1337:2).

Tabel 2. Nilai factor untuk liquid limit alat fall cone metode one-point.

Cone Penetrometer

\begin{tabular}{|c|c|c|c|}
\hline$(\mathrm{mm})$ & Below 35\% & $35 \%$ to $50 \%$ & Above 50\% \\
\hline 15 & 1.057 & 1.094 & 1.098 \\
\hline 16 & 1.052 & 1.076 & 1.075 \\
\hline 17 & 1.042 & 1.058 & 1.055 \\
\hline 18 & 1.030 & 1.039 & 1.036 \\
\hline 19 & 1.015 & 1.020 & 1.018 \\
\hline 20 & 1 & 1 & 1 \\
\hline 21 & 0.984 & 0.984 & 0.985 \\
\hline 22 & 0.971 & 0.968 & 0.967 \\
\hline 23 & 0.961 & 0.954 & 0.949 \\
\hline 24 & 0.955 & 0.943 & 0.929 \\
\hline 25 & 0.954 & 0.934 & 0.909 \\
\hline Plasticity & low & intermediate & High \\
\hline
\end{tabular}

Faktor untuk kadar air

Pengujian liquid limit dilakukan dengan dua alat dan dua metode sehingga pada satu lokasi terdapat empat nilai liquid limit. Berikut hasil pengujian liquid limit empat lokasi dengan kedua alat dan kedua metode dapat dilihat pada Tabel 3. 
Tabel 3. Hasil pengujian liquid limit dengan dua alat dan dua metode.

\begin{tabular}{lcccc}
\multirow{2}{*}{ Sampel } & \multicolumn{2}{c}{ LL Alat Casagrande } & \multicolumn{2}{c}{ LL Alat Fall Cone } \\
\cline { 2 - 5 } & Multi-Point & One-Point & Multi-Point & One-Point \\
\hline Cisoka & 74.71 & 78.00 & 73.83 & 73.86 \\
\hline Cibitung & 70.76 & 69.87 & 72.22 & 72.74 \\
\hline Gunung Sarik & 56.01 & 56.19 & 60.37 & 62.33 \\
\hline Jambi & 49.63 & 48.96 & 52.22 & 53.53
\end{tabular}

\section{ANALISIS DATA}

Pada studi ini, terdapat dua analisis data yang dilakukan yaitu mencari hubungan distribusi ukuran butir tanah dengan nilai liquid limit, dan mencari hubungan nilai liquid limit antara alat dan metode. Berikut adalah hasil analisis data yang dilakukan dapat dilihat pada Tabel 4 dan Tabel 5.

Tabel 4. Hasil analisis data distribusi ukuran butir tanah dengan nilai liquid limit.

\begin{tabular}{lccccccccc}
\multirow{2}{*}{ Sampel } & \multicolumn{2}{c}{$\begin{array}{c}\text { \% finner } \\
\text { Fine }\end{array}$} & \multirow{2}{*}{ Silt } & \multirow{2}{*}{ Clay } & \multicolumn{2}{c}{ LL Alat Casagrande } & \multicolumn{2}{c}{ LL Alat Fall Cone } \\
& \#40 & \#200 & sand & & & Multi-Point & One-Point & Multi-Point & One-Point \\
\hline Cisoka & 94.46 & 89.40 & 5.06 & 61.52 & 27.88 & 74.71 & 78.00 & 73.83 & 73.86 \\
\hline Cibitung & 90.82 & 89.64 & 1.18 & 70.39 & 19.25 & 70.76 & 69.87 & 72.22 & 72.74 \\
\hline Gn. Sarik & 90.26 & 79.98 & 10.28 & 52.43 & 27.55 & 56.01 & 56.19 & 60.37 & 62.33 \\
\hline Jambi & 96.18 & 86.24 & 9.94 & 50.67 & 35.57 & 49.63 & 48.96 & 52.22 & 53.53
\end{tabular}

Hasil analisis data distribusi ukuran butir tanah dengan nilai liquid limit dalam bentuk grafik dapat dilihat pada Gambar 2, Gambar 3, dan Gambar 4.
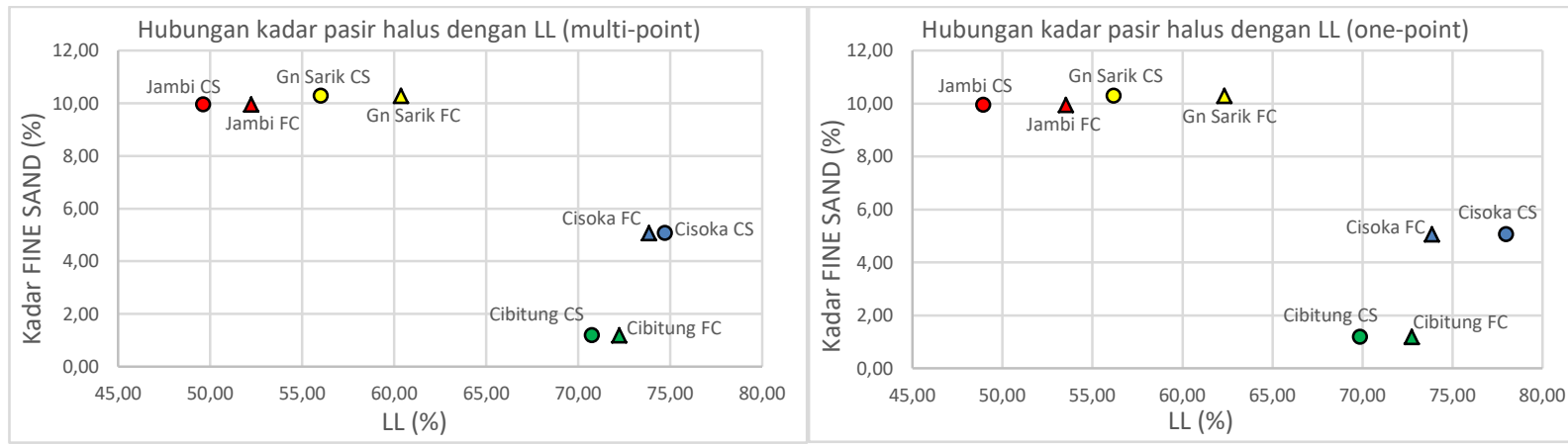

Gambar 2. Hubungan kadar pasir halus dengan liquid limit metode multi-point (kiri) dan one-point (kanan).
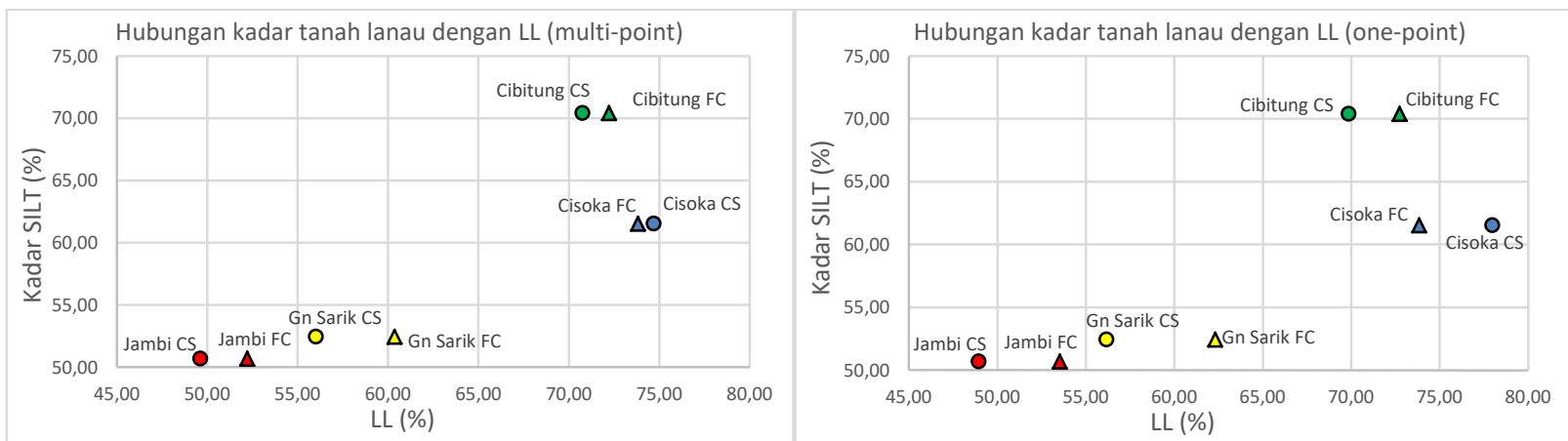

Gambar 3. Hubungan kadar tanah lanau dengan liquid limit metode multi-point (kiri) dan one-point (kanan). 


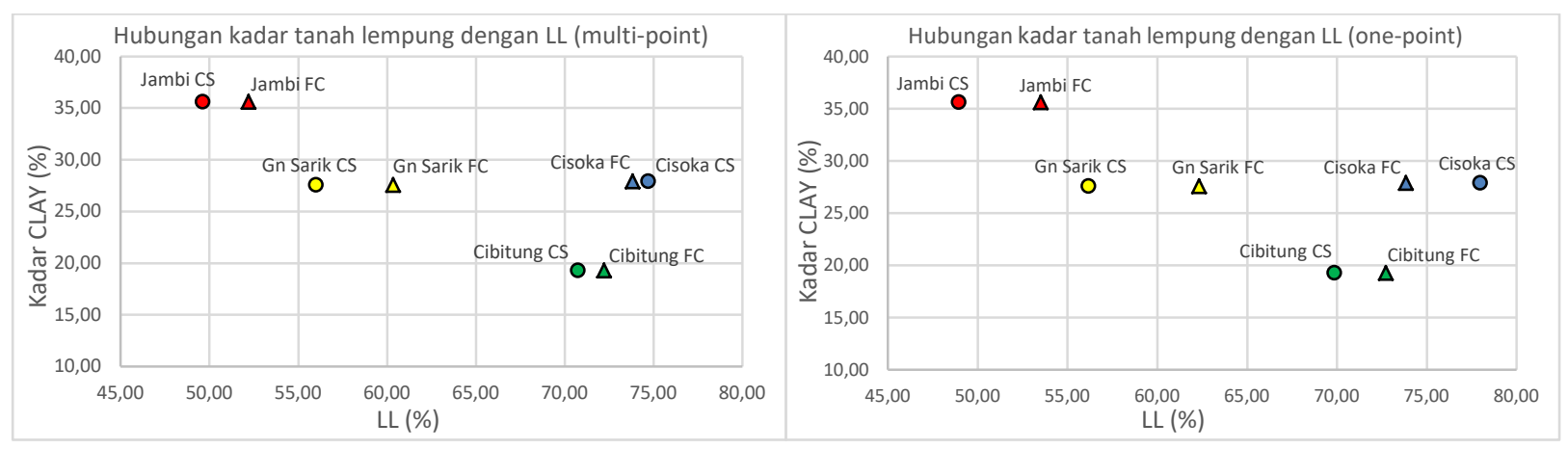

Gambar 4. Hubungan kadar tanah lempung dengan liquid limit metode multi-point (kiri) dan one-point (kanan).

dengan LL = liquid limit, $\mathrm{CS}=$ Casagrande, dan FC = fall cone .

Berdasarkan hasil analisis data tersebut untuk hubungan distribusi ukuran butir tanah dengan nilai liquid limit tidak diperoleh korelasi yang signifikan sehingga tidak dapat disimpulkan secara spesifik, namun pada jumlah sampel tanah yang memiliki kadar pasir halus di atas 7\% cenderung memiliki nilai liquid limit yang rendah. Studi ini hanya dilakukan berdasarkan sifat fisik tanah saja tanpa menganalisa mineral maupun unsur kimia yang terkandung dalam sampel tanah.

Tabel 5. Hasil analisis data hubungan nilai liquid limit antara alat dan metode.

\begin{tabular}{lcccccccc}
\multirow{2}{*}{ Lokasi } & \multicolumn{3}{c}{ LL multi-point (\%) } & \multicolumn{3}{c}{ LL one-point (\%) } & \multicolumn{2}{c}{$\Delta$ LL one X multi } \\
\cline { 2 - 10 } & Casagrande & Fall Cone & $\Delta$ LL & Casagrande & Fall Cone & $\Delta$ LL & Casagrande & Fall Cone \\
\hline Cisoka & 74.71 & 73.83 & 0.88 & 78.00 & 73.86 & 4.13 & 3.28 & 0.03 \\
\hline Cibitung & 70.76 & 72.22 & 1.46 & 69.87 & 72.74 & 2.88 & 0.89 & 0.52 \\
\hline Gunung Sarik & 56.01 & 60.37 & 4.35 & 56.19 & 62.33 & 6.14 & 0.18 & 1.96 \\
\hline Jambi & 49.63 & 52.22 & 2.59 & 48.96 & 53.53 & 4.57 & 0.67 & 1.31
\end{tabular}

Berdasarkan hasil analisis data tersebut untuk hubungan nilai liquid limit antara alat dan metode memiliki perbedaan yang tidak terlalu signifikan dengan perbedaan terbesar pada hubungan antara alat terdapat pada metode one-point sebesar $6.14 \%$ dan perbedaan terbesar pada hubungan antara metode terdapat pada alat Casagrande sebesar 3.28\%. Sehingga penggunaan kedua alat dan metode baik untuk dilakukan dengan syarat sampel tanah yang akan diuji memiliki kadar tanah berbutir halus di atas 50\%.

Hasil analisis data hubungan nilai liquid limit antara alat dan metode dapat dilihat pada Gambar 5 dan Gambar 6.
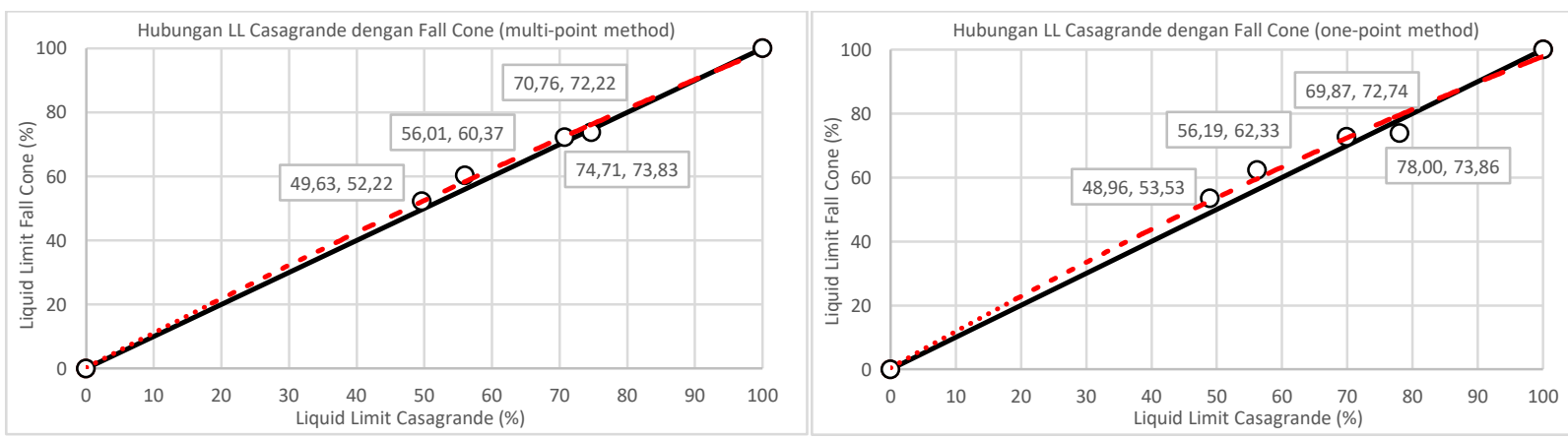

Gambar 5. Hubungan liquid limit alat Casagrande dengan alat fall cone metode multi-point (kiri) dan one-point (kanan). 

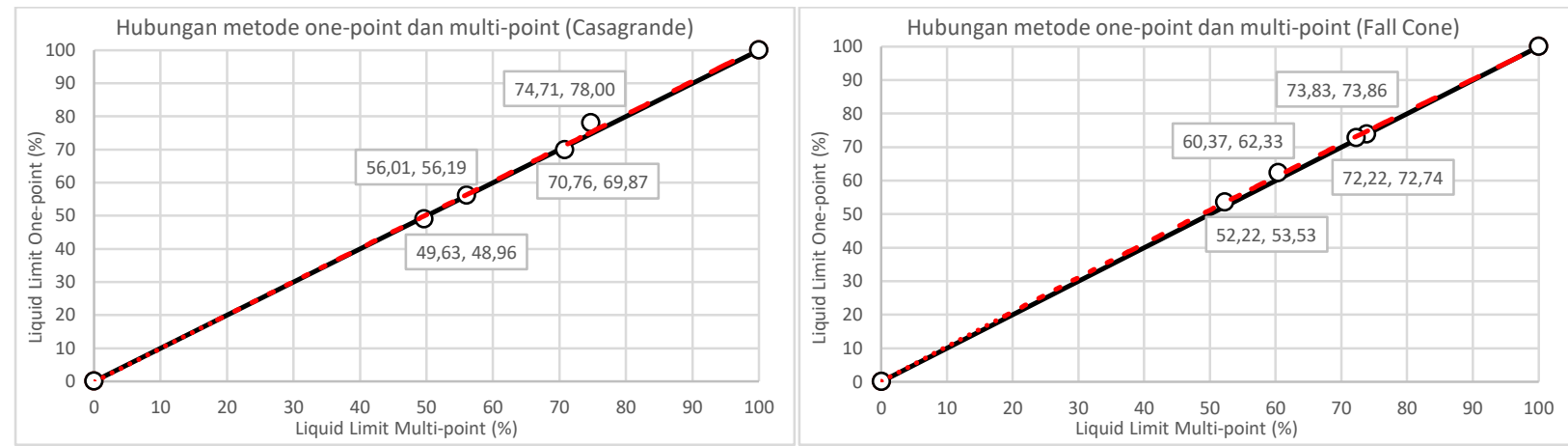

Gambar 6. Hubungan liquid limit metode metode multi-point dengan one-point menggunakan alat Casagrande (kiri) dan fall cone (kanan).

\section{KESIMPULAN}

Dalam studi ini diperoleh beberapa kesimpulan yaitu:

1. Hubungan antara distribusi ukuran butir tanah dengan liquid limit tidak dapat menemukan hasil yang spesifik. Sehingga hubungan distribusi ukuran butir tanah tidak dapat digunakan sebagai acuan untuk menentukan nilai liquid limit.

2. Berdasarkan pengujian liquid limit menggunakan alat Casagrande dan alat fall cone dengan metode multipoint dan one-point, menghasilkan nilai yang hampir sama. Sehingga pengujian liquid limit menggunakan alat Casagrande dan alat fall cone baik dengan metode multi-point maupun one-point dapat digunakan sebagai pengujian untuk penentuan liquid limit, namun pada penggunaan alat fall cone dapat digunakan sebagai alat untuk menentukan nilai liquid limit dengan syarat tanah tersebut merupakan kategori tanah berbutir halus atau mengandung lempung.

\section{DAFTAR PUSTAKA}

American Society for Test and Materials (1998), “ASTM D 422 - 63, Standard Test Method for Particle-Size Analysis of Soils”, ASTM International, West Conshohocken.

American Society for Test and Materials (2000), “ASTM D 4318 - 00, Standard Test Methods for Liquid Limit, Plastic Limit, and Plasticity Index of Soils”, ASTM International, West Conshohocken.

American Society for Test and Materials (2002), “ASTM D 854 - 02, Standard Test Methods for Specific Gravity of Soils Solids by Water Pycnometer”, ASTM International, West Conshohocken.

British Standard (1990), "BS 1377 - 2, Methods of test for Soils for civil engineering purposes - part 2: Classification tests”, British Standard Institution, London.

Garcia-Gaines, R. A. (2015), “USCS and the USDA Soil Classification System”, U.S. Army Engineer Research and Development Center.

Sivakumar, V. et al. (2009), “A New Method of Measuring Plastic Limit of Fine Materials”, Ge'otechnique 59, No.10, 813823 [doi: 10.1680/geot. 2009. 59. 10.813].

Sutarman, E. (2013), “Konsep dan Aplikasi Mekanika Tanah”, ANDI, Yogyakarta. 